\title{
Milieu-Dependent Pro- and Antioxidant Activity of Juglone May Explain Linear and Nonlinear Effects on Seedling Development
}

\author{
V. Chobot • F. Hadacek
}

Received: 3 December 2008 /Revised: 27 January 2009 /Accepted: 10 February 2009/Published online: 5 March 2009

(C) The Author(s) 2009. This article is published with open access at Springerlink.com

\begin{abstract}
Juglone, 5-hydroxy-1,4-naphthoquinone, is known for its wide range of biological activities. It has been suggested that juglone's excellent redox cycling properties contribute to this reputation. Many biological activities are nonlinear with low concentrations exerting stimulating effects, whereas only higher concentrations cause inhibition. Here, we corroborate studies on the nematode Caenorhabditis elegans that point out hormetic effects by showing that juglone may cause a nonlinear effect on postgerminative shoot and root growth of Sinapis alba. This effect was only significantly visible, however, when seedlings were stressed with methanol. Classic and modified versions of the deoxyribose assay were applied successfully to characterize antioxidative (purposeful generation of hydroxyl radicals) and prooxidative (no purposeful generation of hydroxyl radicals) activities. Variants of the assay with and without the addition of the iron chelator EDTA showed that the antioxidant activity is independent on chelation of iron ions by juglone; by contrast, the strength of the prooxidative activity depended on the chelation of iron ions by juglone. The hormetic effects of lower concentrations on germination of Sinapis alba, thus, may be caused by the antioxidant activities of this compound, which are especially effective when the test organism is subjected to higher oxidative challenge. The present study suggests that pronounced prooxidative activities, which are considerably accelerated by chelation of
\end{abstract}

V. Chobot $\cdot$ F. Hadacek $(\bowtie)$

Department of Chemical Ecology and Ecosystem Research,

Faculty of Life Sciences, University of Vienna,

1090 Vienna, Austria

e-mail: franz.hadacek@univie.ac.at iron ions, may contribute to the toxic effects of juglone at higher concentrations.

Keywords Naphthoquinones $\cdot$ Sinapis alba Inhibition Hormesis $\cdot$ ROS $\cdot$ Fenton reaction $\cdot$ Chelation of iron · Stress

\section{Introduction}

Although the need for greater use of modern technology and additional research on allelopathic mechanisms has been articulated (Romeo 2000), this area remains somewhat neglected relative to traditional phytotoxicity experiments. A few recent studies include those on: juglone effects on root plasma membrane $\mathrm{H}^{+}$ATPase activity and root water uptake (Hejl and Koster 2004); the use of polydimethylsiloxane materials to quantify levels of the photosynthesis inhibitor sorgoleone in the rhizosphere of sorghum plants (Weidenhamer 2005); the critical evaluation of the contribution of $( \pm$ )-catechin to invasion success of spotted knapweed (Blair et al. 2005, 2006); degradation of soluble phenolics by ectomycorrhizal fungi, thus controlling species interactions in black spruce stands (Zeng and Mallik 2006); selective phytotoxicity of L-DOPA because of differential polyphenol oxidase activity in barnyard grass and lettuce, thus mediating reactive oxygen species and/or free radical species (Hachinohe and Matsumoto 2007); and differential gene expression in rice under low nitrogen due to stronger activation of genes that function in synthesis of allelochemicals (Song et al. 2008).

Often, we do not pay much attention to studies carried out many decades ago, simply because, compared to current standards, the methodologies have dramatically changed. Hans Molisch is generally regarded as the person coining 
the term allelopathy. In his experiments, he used the odor of apple peels, mainly comprised of ethylene, as a model system to explore effects of volatile emissions on the development of a range of plant species. He reported the results in his famous booklet "Der Einfluß der Pflanze auf die andere, Allelopathie" (the effect of one plant on another, allelopathy); there also exists an English translation (Molisch 2002). Molisch's observations contain some fundamental insights, which are still under discussion today. In the summary, Molisch notes: "If seedlings are only exposed to the gas emitted by apples a relatively short time, then it becomes evident, that not an inhibition of longitudinal growth occurs but a very pronounced stimulation. Exposure to apple odor for one to five hours caused an unambiguous stimulation, whereas 24 hours caused a slight inhibition that became more pronounced with ongoing exposure". He also provides an interpretation: "Here, the often observed rule is confirmed that poisons and irritating compounds are harmful in higher concentrations, but stimulate in diluted form". The last sentence is especially notable, because Molisch (1937) already acknowledges a nonlinear mode of action for allelochemicals. In many instances, the response of living organisms to abiotic or biotic effectors is nonlinear, i.e., at low dosages the response is opposite to that of high ones; high doses inhibit growth and low doses stimulate growth. The latter phenomenon is also known by the term hormesis (Calabrese et al. 2007). Although it has been known for a long time, it has been largely ignored because nobody could explain it (Stebbing, 1982). Allelopathic studies that address the phenomenon of hormesis are infrequent, and then the phenomenon is addressed usually only peripherally (Romagni et al. 2000; Belz 2008). However, it has been focused on recently in ecological modeling of allelopathy (Sinkkonen 2007). In their recent survey of hormesis in plant biology, Calabrese and Blain (2009) note that allelopathy is a rapidly developing area in plant chemical biology in which hormetic responses of chemical exudates from plant roots are to be considered.

Juglone, 5-hydroxy-1,4-naphthoquinone, is classified as a strong redox cycler with high potential to react with oxygen and its reactive species. Thereby, it interferes with vital cell processes such as photosynthesis, respiration, cell division, and membrane transport (Bertin et al. 2003; Tomilov et al. 2006). Among others, one of the noted harmful effects is the alleged role in the allelopathy of walnut trees (Jose 2002). In an attempt to optimize simple tube assay procedures, thus allowing us to explore the potential redox reactions of allelochemicals, modified variants of the deoxyribose assay were used. This assay was developed as a simple screening method for hydroxyl radical scavengers (Aruoma et al. 1987; Halliwell et al. 1987). The recognized function of juglone as a redox cycler distinguishes this allelochemical as a suitable model for exploring the combined applicability of simple tube assays with biological assays to obtain further insights about the milieu-dependent reactivity of candidate molecules. In this study, the effects of juglone on seedling development of Sinapis alba served as the biological assay. In consideration of the proposed role of reactive oxygen species (ROS) in the mode of action of juglone, we used an agar- and filter paper-based growth assay to simulate low and high level of oxidative stress caused by variable additions of methanol ( 0.2 and $10 \%, v / v$, respectively) to the medium. We expected to detect nonlinear effects (hormesis) at higher methanol levels. Hormetic abilities previously have been reported for effects of juglone on the genetic model nematode Caenorhabditis elegans; these effects became especially evident when $C$. elegans was pretreated with low dosages of heat, hyperbaric oxygen, or even juglone itself, and then subjected to subsequent stresses of the original or one of the other stressors (Cypser and Johnson 2002).

\section{Materials and Methods}

Chemicals All chemicals were obtained from Sigma Aldrich Inc. (St. Louis, MO, USA) unless otherwise stated; water had Milli-Q quality.

Antioxidative Assays Procedures followed those described by Halliwell et al. (1987) and Aruoma (1994) for the deoxyribose assay. Juglone (Fluka, Buchs, Switzerland) was dissolved in an aqueous $\mathrm{KH}_{2} \mathrm{PO}_{4} / \mathrm{KOH}$ buffer solution (50 mM, pH 7.4) to yield final concentrations of 2$500 \mu \mathrm{M}$. To $125 \mu \mathrm{l}$ of this solution, $25 \mu \mathrm{l}$ of a $10.4 \mathrm{mM}$ 2-deoxy-D-ribose solution in the same buffer system and $50 \mu \mathrm{l}$ of an aqueous solution of $\mathrm{FeCl}_{3}(50 \mu \mathrm{M})$ were added. In one series of the assay, those $50 \mu \mathrm{l}$ contained $52 \mu \mathrm{M}$ EDTA in buffer, and in the other series, only buffer was added. To start the Fenton reaction, various reactants dissolved in the above mentioned buffer systems or in water were added: $25 \mu \mathrm{l} 10.0 \mathrm{mM}$ aqueous solution of $\mathrm{H}_{2} \mathrm{O}_{2}$ and $25 \mu \mathrm{l} 1.0 \mathrm{mM}$ ascorbic acid in buffer. Standard $1.5 \mathrm{ml}$ sample vials (La-Pha-Pack, Werner Reifferscheidt $\mathrm{GmbH}$, Langerwehe, Germany) were used as reaction vials. The mixture was vortexed and incubated at $27^{\circ} \mathrm{C}$ for $60 \mathrm{~min}$. Thereafter, $10 \mu \mathrm{l}$ of $2.5 \%$ ethanolic butylated hydroxytoluene solution followed by $250 \mu \mathrm{l}$ of $1.0 \% 2$ thiobarbituric acid dissolved in 3\% trichloroacetic acid were added to each vial to detect malonyldialdehyde, the decomposition product of 2-deoxy-D-ribose caused by the attack of hydroxyl radicals. The vials were vortexed and heated in a water bath at $85^{\circ} \mathrm{C}$ for $30 \mathrm{~min}$. The reaction was stopped by transferring the vials into an ice water bath for $3 \mathrm{~min}$. To extract the reaction product of malonyldialdehyde 
and thiobarbituric acid, $600 \mu$ of $n$-butanol was added and the mixture was rigorously vortexed. The butanol layers of the vials, each $350 \mu$, were pipetted into flat-bottomed 96well plates (Greiner, Kremsmünster, Austria), and the absorbance was determined with a microplate reader (Tecan Infinite M200, Männedorf, Switzerland) at 532 nm. Assays were performed in triplicate. Reaction mixtures lacking the test compound served as negative controls. Blank was reactive mixture without 2-deoxy-D-ribose.

Prooxidative Assays This modification of the deoxyribose assay was carried out without the addition of $\mathrm{H}_{2} \mathrm{O}_{2}$ and ascorbic acid. Reactions of juglone depended strongly on the dissolving of oxygen into the liquid. Thus, scoring was performed after $16 \mathrm{~h}$.

\section{Postgermination Growth Assays (Low Stress Scenario)}

Seeds of $S$. alba L. were obtained from B and T World Seeds (Paguignan, France) and surface sterilized (1 min in $70 \%$ EtOH). Petri dishes (9 $\mathrm{cm}$ diam, Greiner Bio-One, Kremsmünster, Austria) were prepared with solidified Murashige and Skoog (MS) basal medium and spiked with a methanolic solution of juglone to provide concentrations of 6-200 $\mathrm{g} \mathrm{m} \mathrm{ml}^{-1}$ juglone in the agar medium. Controls were spiked with methanol alone $(0.2 \% v / v)$. Surfacesterilized seeds were transferred to the agar medium with sterilized forceps. Petri dishes were incubated at $25 \pm 2^{\circ} \mathrm{C}$ in dark. After 5 days, control and treated seedlings were photographed with an Olympus D500 digital camera equipped with a $35 \mathrm{~mm}$ macro lens (Olympus Corporation, Tokyo, Japan). Image analysis was carried out for shoots and roots separately using Image J $1.36 \mathrm{~b}$ (Wayne Rasband, $\mathrm{NH}$, USA). Means of the pixel counts of the control seedlings were determined as $100 \%$ growth.

\section{Postgermination Growth Assays (High Stress Scenario)}

Filter paper disks (Schleicher and Schuell 520 B 1/2, $60 \mathrm{~mm}$ diam) were moistened with $1 \mathrm{ml}$ of a $10 \%$ methanolic aqueous solution containing the test compound in concentrations of 6-200 $\mathrm{g} \mathrm{m} \mathrm{ml}^{-1}$. The moistened filter papers were placed in 9-cm Petri dishes. Surface-sterilized seeds were transferred to the filter paper with sterile forceps. Petri dishes were kept sealed for $48 \mathrm{~h}$; then, the sealing tape was removed and the methanol was allowed to evaporate. Water was added to replenish the liquid and to keep the filter paper moistened. Scoring was performed as previously described. The assay was performed in dark at $25^{\circ} \mathrm{C}$ and scoring was performed after 5 days.

Statistics Statgraphics Plus 5.0 (Statistical Graphics Corp., Rockville, MD, USA) was used for statistics. MannWhitney rank test and analyses of variance (ANOVA) with Duncan's multiple range tests were performed at a confidence level of $95 \%$.

\section{Results and Discussion}

In the following text, we illustrate a number of reactions that aim to support our interpretation of the results obtained from the deoxyribose decomposition assays including one and two electron transfers. We stress that these reactions represent only a selection of possible ones, the majority of which probably are running simultaneously and reversibly. They are aimed at providing evidence that possible reactions exist that support the assay results.

Juglone proved to be a strong scavenger of hydroxyl radicals $\left({ }^{\circ} \mathrm{OH}\right)$ in the deoxyribose assay (Fig. 1a). In this setup, ascorbic acid reduces iron (III) to iron (II). Ascorbic acid is oxidized to dehydroascorbic acid (1).

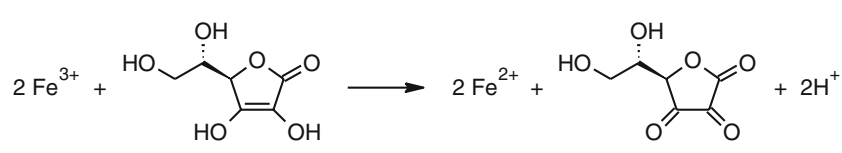

The same assay also was performed with the addition of EDTA, which efficiently chelates the iron ions but does not prevent iron from participating in further redox reactions. Consequently, ascorbic acid also reduced the EDTAcomplexed iron (2).

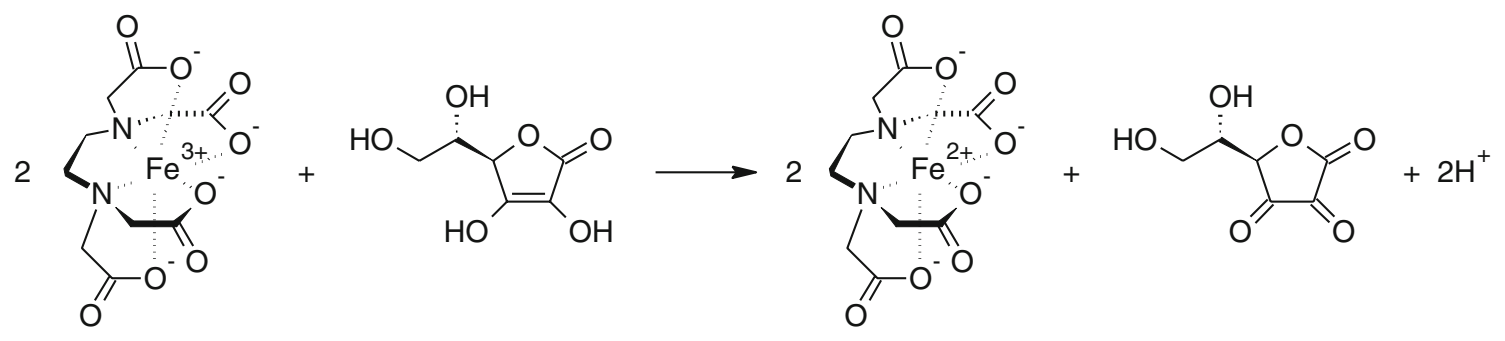


In our setup of the assay, the antioxidant activity was comparable to the variant without EDTA (Fig. 1a). This implies that chelation of iron by juglone does not affect its antioxidant activity. The reduced iron $\left(\mathrm{Fe}^{2+}\right)$, both in its free form (3) and as complex (4), reacts with hydrogen peroxide in the Fenton reaction and generates hydroxyl radicals, which are strong enough to decompose 2-deoxy-D-ribose to malonyldialdehyde (Aruoma et al. 1987; Aruoma 1994).

$$
\mathrm{Fe}^{2+}+\mathrm{H}_{2} \mathrm{O}_{2} \longrightarrow \mathrm{Fe}^{3+}+\mathrm{OH}+\mathrm{OH}^{-}
$$

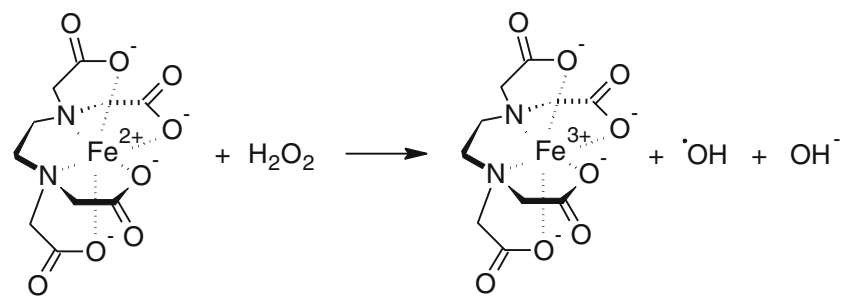

The hydroxyl radical also may arise by one electron transfers between the semiquinone of reduced juglone and hydrogen peroxide $(5,6)$.
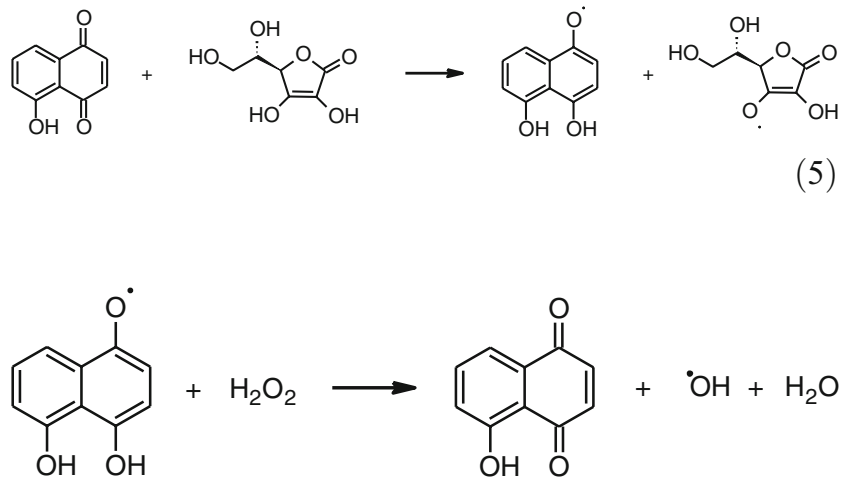

The fundamental reaction of the antioxidant activity of juglone is most likely the reduction of hydroxyl radicals to water (7).<smiles></smiles>

Alternatively, juglone may oxidize hydrogen peroxide to oxygen and thereby get reduced to trihydroxynaphthalene
(8). The latter compound may be a more powerful reducing agent than juglone itself.<smiles>CC(C)CCO[NH3+]</smiles>

These reactions are possible at a more or less neutral $\mathrm{pH}$ (the $\mathrm{pH}$ of the aqueous buffer was adjusted to 7.4, thus resembling the milieu in the cytosol); at a lower $\mathrm{pH}$, such as in the vacuole, they are less likely to work. In neutral milieu, juglone also may chelate iron ions (the chelation is both possible for iron (III) and iron (II) ions; the former are illustrated [9]). However, for antioxidant activity, chelation of iron ions by juglone did not affect the efficacy of the reaction.

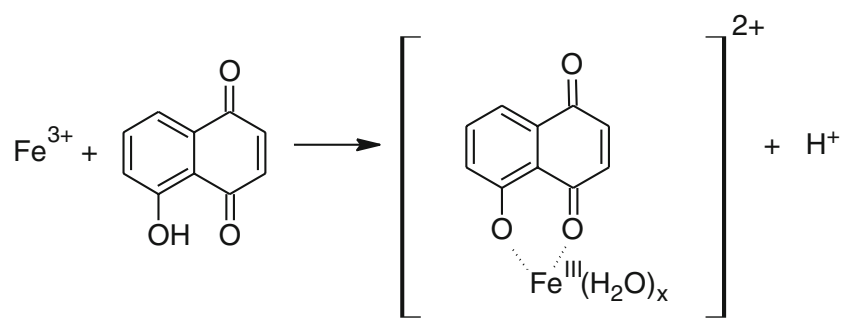

In an attempt to obtain a tube assay that also facilitates the detection of prooxidative effects, the deoxyribose assay was modified. In this variant, hydrogen peroxide and ascorbic acid were not added. The duration of the assay was increased to $16 \mathrm{~h}$ to facilitate detection of reactions with oxygen dissolved in the aqueous buffer. Juglone showed a pronounced prooxidative effect as expected (Fig. 1b). Again, two setups were performed, one with addition of EDTA, the other without. However, the prooxidative activity of juglone was much more pronounced if EDTA was not added. This difference merits attention. Due to the absence of low concentration of free radicals, molecular oxygen is reduced to superoxide by juglone (10).<smiles>CC(C)c1ccc2c(c1O)C(=O)C=[C+]CC2=O</smiles> 


\section{a}

2-Deoxy-D-ribose $+\mathrm{FeCl}_{3}+\mathrm{H}_{2} \mathrm{O}_{2}+$ ascorbic acid (1h); black bars: no EDTA added; white bars: EDTA added

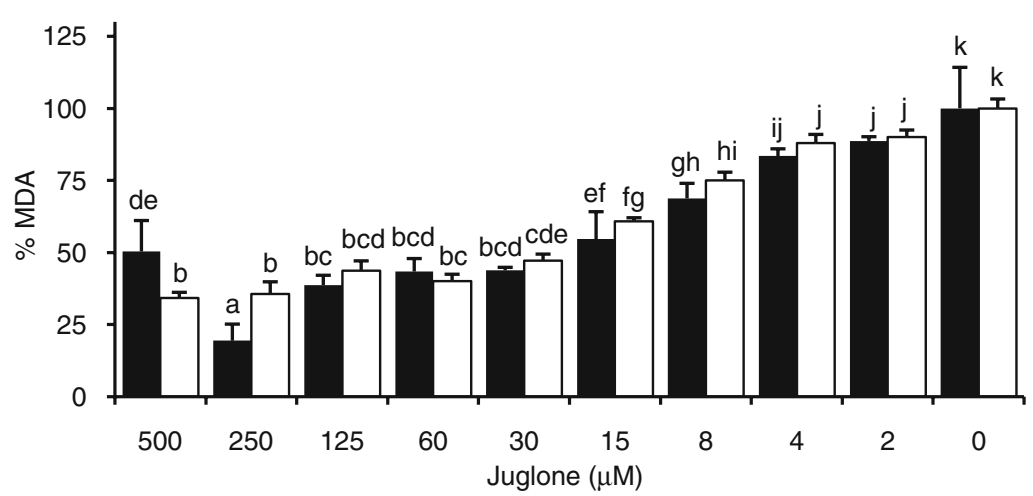

b

2-Deoxy-D-ribose + $\mathrm{FeCl}_{3}(16 \mathrm{~h})$;

black bars: no EDTA added; white bars: EDTA added

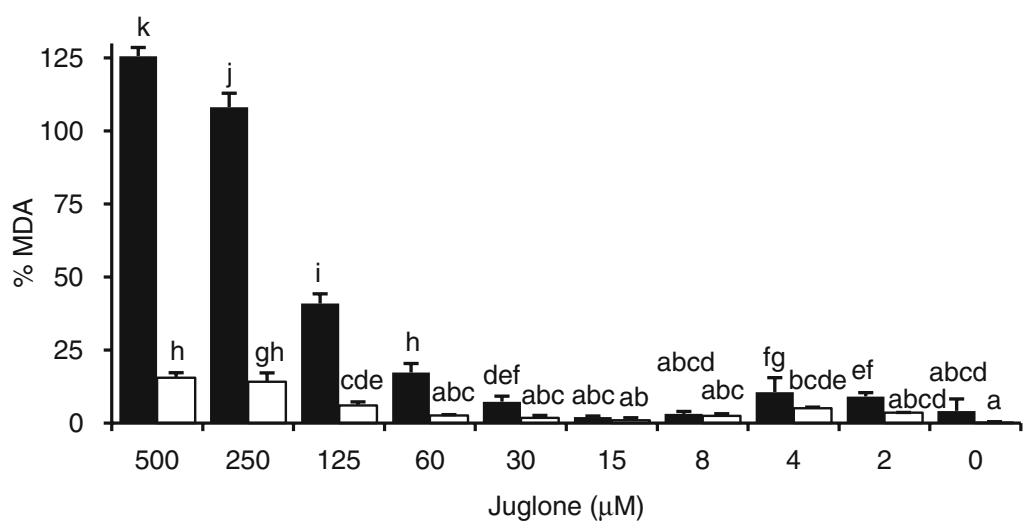

C

Postgerminative shoot growth (5d);

white bar: MS agar medium, $0.2 \% \mathrm{MeOH}(\mathrm{v} / \mathrm{v})$

added; black bars: filter paper, $10 \% \mathrm{MeOH}(\mathrm{v} / \mathrm{v})$

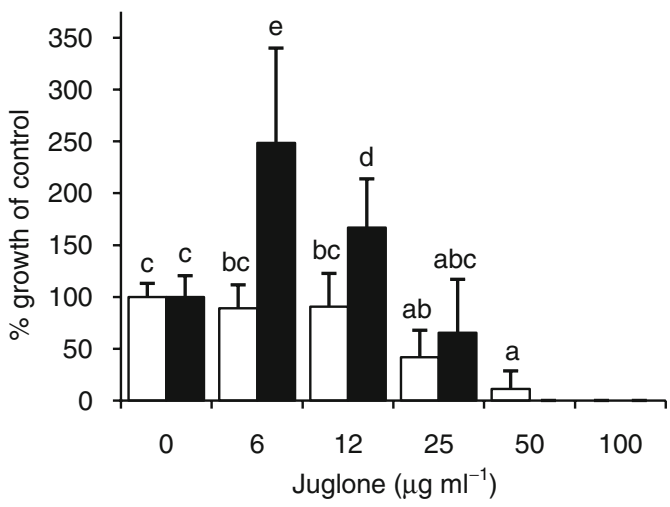

d

Postgerminative root growth (5d); white bar: MS agar medium, $0.2 \% \mathrm{MeOH}(\mathrm{v} / \mathrm{v})$ added; black bars: filter paper, $10 \% \mathrm{MeOH}(\mathrm{v} / \mathrm{v})$

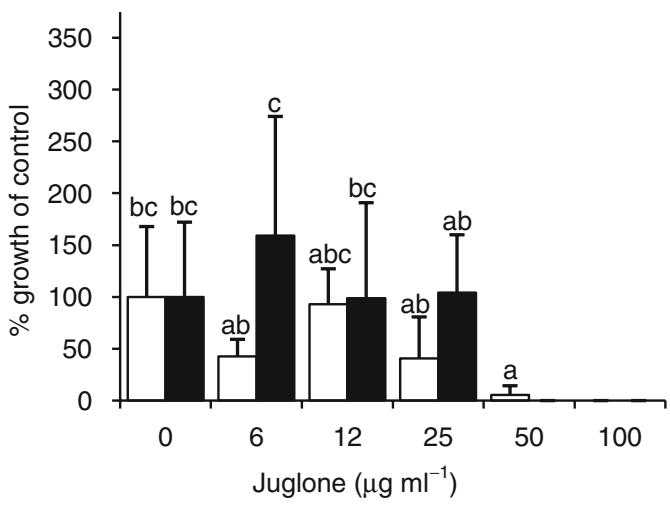

Fig. 1 a Antioxidative activity of juglone, quantified in \% malonyldialdehyde, an oxidative decomposition product of 2-deoxy-D-ribose; bars, means; error bars, standard deviation; $N=3$, letters indicate different levels of significance ( $95 \%$ probability, Duncan's multiple range test). b Prooxidative activity of juglone; for specific information, see antioxi-

Superoxide can react with itself (dismutation of superoxide, [11]).

$2 \mathrm{O}_{2}^{--}+2 \mathrm{H}^{+} \longrightarrow \mathrm{H}_{2} \mathrm{O}_{2}+\mathrm{O}_{2}$

Superoxide may also directly react with the formed hydrogen peroxide generating hydroxyl radicals conditional to the presence of iron (12). dant activity; scale of $100 \%$ MDA scale is the same as in (a). c Postgerminative shoot growth, quantitative biological assay; bars, means; error bars, standard deviation; $N=5$; letters indicate different levels of significance ( $95 \%$ probability, Duncan's multiple range test). d Postgerminative root growth; for specific information, see shoot growth

$$
\stackrel{\circ--}{\mathrm{O}_{2}}+\mathrm{H}_{2} \mathrm{O}_{2} \stackrel{\mathrm{Fe}^{3+}}{\longrightarrow} \mathrm{O}_{2}+\cdot \cdot \mathrm{OH}+\mathrm{OH}^{-}
$$

The results suggest that chelation of iron by different molecules affects the electrochemical potential required for reduction of iron (III) (Miller et al. 1990). If EDTA is added, juglone reduces the EDTA complex of iron (III) (13).<smiles>CCCN(CC(=O)O)CC(=O)OC(=O)[C@@H](O)C(=O)[O-]</smiles> 
If no EDTA is added, then iron (III) is chelated by juglone and-as suggested by the pronounced activity visible at higher concentrations tested-reduced to iron (II) in the complex (14).

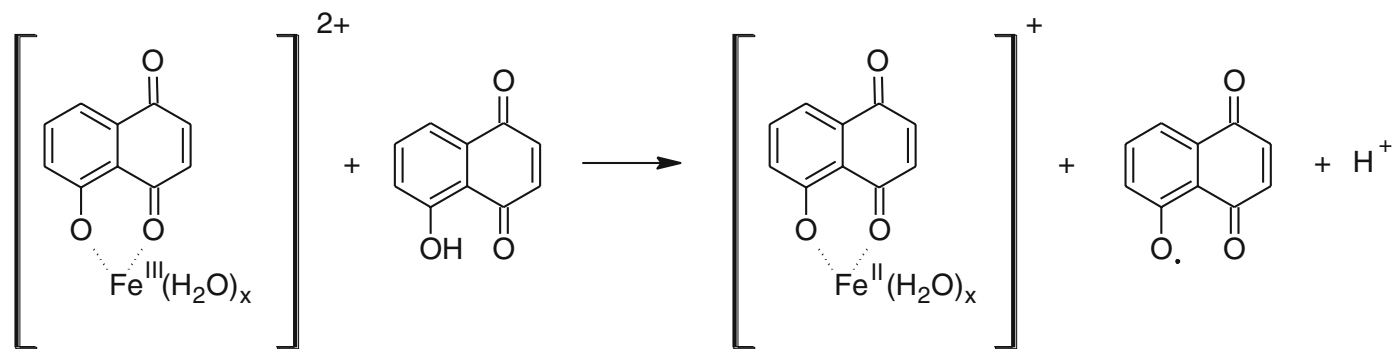

For the juglone-iron (III) complex, the required energy for the reduction seems to be considerably lower. As a consequence, more juglone-chelated iron (II) is available for the generation of hydroxyl radicals in a Fenton type reaction (15) than EDTA-chelated iron (II) in the other setup.

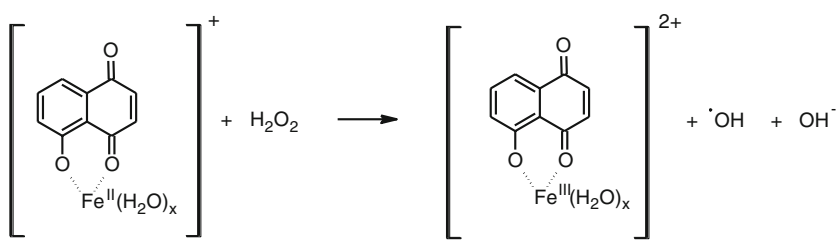

Within the tested range of concentrations, the prooxidative effect was linear. It is possible that the nonlinearity in the antioxidant setup, where no EDTA was added, may be caused by the reactions leading to the prooxidative effect as described above.

By starting from the notion that juglone is an efficient redox cycler, we wanted to explore if juglone might cause nonlinear effects in biological assays, hormesis - a process whereby test organisms exposed to low levels of stress or toxins become relatively more resistant to subsequent challenges. In the present case, we expected low levels of juglone to ameliorate the stress caused by higher methanol concentrations. In vivo oxidation of methanol may generate superoxide, thus causing toxic effects in living organisms. The addition of methanol to aqueous solutions may not only be employed to improve dispersion of lipophilic compounds in aqueous media - as is good laboratory practice-but also to increase stress for the tested organism. Thus, to create a low- and high-stress setup of the postgermination growth assay, S. alba was germinated on MS agar medium $(<0.2 \%$ $\mathrm{MeOH})$ and on filter paper assay $(10 \% \mathrm{MeOH})$. The results are illustrated by Fig. 1c and d. Shoot size of the seedlings exposed to higher methanol concentration was nearly half the size of seedlings exposed to the low methanol concentration ( $P=0.005$, Mann-Whitney rank test). Figure 1c and d illustrate the postgerminative growth dynamics as $\%$ in relation to the control; thus, the inhibitory effect of the higher methanol concentration is not evident, as both means of the control denote $100 \%$.

Root development was not significantly affected by the various methanol concentrations ( $P=0.689$, Mann-Whitney rank test). At lower methanol concentrations $(<0.2 \%)$, increasing concentrations of juglone inhibited postgermination growth of $S$. alba seedlings clearly affecting the shoot and less evidently the root; $100 \mu \mathrm{g} \mathrm{ml} \mathrm{ml}^{-1}$ completely inhibited germination. The concentration of the solution of juglone in the agar was about $575 \mu \mathrm{M}$. At the same concentration range, the deoxyribose degradation assay suggests that juglone may cause a pronounced prooxidative effect when levels of free radicals are low (Fig. 1b). In the filter paper assay (the initial concentration of methanol was around 10\%), germination was inhibited at $50 \mu \mathrm{g} \mathrm{ml}$ (287 $\mu \mathrm{M})$. Although, at $6 \mu \mathrm{g} \mathrm{ml}^{-1}(34 \mu \mathrm{M})$, a significant stimulatory effect was visible (Fig. 1c). This stimulation of lower juglone concentrations was especially visible in the shoot development, which similarly was more affected by higher methanol concentrations. The roots were less affected and, accordingly, were less stimulated by lower juglone concentrations. At the low concentrations where the stimulatory and thus hormetic effect was visible $( \pm 30 \mu \mathrm{M})$, the deoxyribose degradation assay suggests that juglone may efficiently scavenge present hydroxyl radicals. This also reflects a mitigating effect on the stress when the seeds were exposed to high methanol concentrations.

Cypser and Johnson (2002) observed a similar hormetic effect of juglone in gerontological studies that used the nematode $C$. elegans as a test organism. In that study, pretreatment with the toxin juglone mitigated oxygen stress. Conversely, preceding oxygen stress also mitigated stress caused by the application of juglone. These authors concluded that low levels of initial oxidative stress 
obviously mitigate effects of subsequent stressors that cause oxidative stress. Here, we demonstrated that juglone can scavenge hydroxyl radicals generated by Fenton type reactions during oxidative stress in a chemical assay. In our biological assay, a hormetic effect was visible only when seeds of $S$. alba were stressed with $10 \%$ methanol in the solution. The results suggest that the hormetic effect of a redox cycling compound (in this regard, juglone represents an efficient example) may be caused by scavenging ROS such as the hydroxyl radical.

Juglone is a potent bioactive compound. Can this compound, however, serve as an effective chemical defense, for example, in the case of allelopathy of the walnut tree? This question is difficult to answer, as it is difficult to develop one ideal assay to measure pro- and antioxidative activities (Halliwell and Gutteridge 1995). Hormetic activity may be determined not only by structural characteristics and concentration, but also-as our results suggest - be facilitated by the milieu in the tissues of the targeted organism. The results presented here provide ideas for explaining hormesis caused by juglone. Evolution may favor such potent redox cyclers. Gene expression studies in Arabidopsis thaliana and rice have shown that juglone (Mylona et al. 2007), herbicides such as paraquat and glyphosate (Ahsan et al. 2008), and even hormones such as abscisic acid (Guan et al. 2000), may by generating ROS provoke similar effects in the expression patterns of antioxidant genes. This suggests that common stressrelated motifs in the promoters of these genes should be present (Mylona et al. 2007). Studies that assess the effect of allelochemicals on cell cycling (Sanchez-Moreiras et al. 2008) should increase our understanding of allelopathy.

Acknowledgements V.C. and the research carried out in this study were supported by a Lise Meitner fellowship of the Austrian Science Fund (FWF M920-B03).

Open Access This article is distributed under the terms of the Creative Commons Attribution Noncommercial License which permits any noncommercial use, distribution, and reproduction in any medium, provided the original author(s) and source are credited.

\section{References}

Ahsan, N., Lee, D. G., Lee, K. W., Alam, I., Lee, S. H., BahK, J. D., and LEE, B. H. 2008. Glyphosate-induced oxidative stress in rice leaves revealed by proteomic approach. Plant Physiol. Biochem. 46:1062-1070.

ARUoma, O. I. 1994. Deoxyribose assay for detecting hydroxyl radicals., pp. 57-66, in H. Sies, J. Abelson, and S. Melvin (eds.). Oxygen radicals in biological systems, Part C 233. Academic, San Diego.

Aruoma, O. I., Grootveld, M., and Halliwell, B. 1987. The role of iron in ascorbate dependent deoxyribose degradationevidence consistent with an site-specific hydroxyl radical generation caused by iron ions bound to the deoxyribose molecule. J. Inorg. Biochem. 29:289-299.
BELZ, R. G. 2008. Stimulation versus inhibition-bioactivity of parthenin, a phytochemical from Parthenium hysterophorus L. Dose-Response 6:80-96.

Bertin, C., YAnG, X. H., and Weston, L. A. 2003. The role of root exudates and allelochemicals in the rhizosphere. Plant Soil 256:67-83.

Blair, A. C., Hanson, B. D., Brunk, G. R., Marrs, R. A., Westra, P., Nissen, S. J., and Hufbauer, R. A. 2005. New techniques and findings in the study of a candidate allelochemical implicated in invasion success. Ecol. Lett. 8:1039-1047.

Blair, A. C., Nissen, S. J., Brunk, G. R., and Hufbauer, R. A. 2006. A lack of evidence for an ecological role of the putative allelochemical (+/-)-catechin in spotted knapweed invasion success. J. Chem. Ecol. 32:2327-2331.

Calabrese, E. J., and Blain, R. B. 2009. Hormesis and plant biology. Environ. Pollut. 157:42-48.

Calabrese, E. J., Bachmann, K. A., Bailer, A. J., Bolger, P. M., Borak, J., Cai, L., Cedergreen, N., Cherian, M. G., Chlueh, C. C., Clarkson, T. W., Cook, R. R., Diamond, D. M., Doolittle, D. J., Dorato, M. A., Duke, S. O., Feinendegen, L., Gardner, D. E., Hart, R. W., Hastings, K. L., Hayes, A. W., Hoffmann, G. R., IVES, J. A., JaWorowski, Z., Johnson, T. E., Jonas, W. B., Kaminski, N. E., Keller, J. G., Klaunig, J. E., Knudsen, T. B., Kozumbo, W. J., Lettleri, T., LiU, S. Z., Maisseu, A., Maynard, K. I., Masoro, E. J., McClellan, R. O., Mehendale, H. M., Mothersill, C., Newlin, D. B., NigG, H. N., Oehme, F. W., Phalen, R. F., Philbert, M. A., Rattan, S. I. S., Riviere, J. E., RODRICKS, J., SAPOLSKY, R. M., SCOTT, B. R., Seymour, C., Sinclair, D. A., SMith-Sonneborn, J., SnOw, E. T., Spear, L., Stevenson, D. E., Thomas, Y., Tubiana, M., Williams, G. M., and Mattson, M. P. 2007. Biological stress response terminology: integrating the concepts of adaptive response and preconditioning stress within a hormetic doseresponse framework. Toxicol. Appl. Pharmacol. 222:122-128.

CYPSER, J. R., and Johnson, T. E. 2002. Multiple stressors in Caenorhabditis elegans induce stress hormesis and extended longevity. J. Gerontol. Ser. A-Biol. Sci. Med. Sci. 57:B109B114.

Guan, L. M., ZhaO, J., and Scandalios, J. G. 2000. Cis-elements and trans-factors that regulate expression of the maize Cat1 antioxidant gene in response to ABA and osmotic stress: $\mathrm{H}_{2} \mathrm{O}_{2}$ is the likely intermediary signaling molecule for the response. Plant J. 22:87-95.

Hachinohe, M., and Matsumoto, H. 2007. Mechanism of selective phytotoxicity of L-3,4-dihydroxyphenylalanine (L-Dopa) in barnyardglass and lettuce. J. Chem. Ecol. 33:1919-1926.

Halliwell, B., and GutTeridge, J. M. C. 1995. The definition and measurement of antioxidants in biological systems. Free Radic. Biol. Med. 18:125-126.

Halliwell, B., GutTeridge, J. M. C., and Aruoma, O. I. 1987. The deoxyribose method - a simple test-tube assay for determination of rate constants for reactions of hydroxyl radicals. Anal. Biochem. 165:215-219.

HeJl, A. M., and Koster, K. L. 2004. Juglone disrupts root plasma membrane $\mathrm{H}(+)$ atpase activity and impairs water uptake, root respiration, and growth in soybean (Glycine max) and corn (Zea mays). J. Chem. Ecol. 30:453-471.

JOSE, S. 2002. Black walnut allelopathy: current state of the science, pp. 149-172, in Inderjit, and A. U. Mallik (eds.). Chemical ecology of plants: allelopathy in aquatic and terrestrial ecosystems. Birkhauser, Basel.

Miller, D. M., Buettner, G. R., and Aust, S. D. 1990. Transitionmetals as catalysts of autoxidation reactions. Free Radic. Biol. Med. 8:95-108.

Molisch, H. 1937. Der Einfluß der einen Pflanze auf die andere: Allelopathie. Jena: Gustav Fischer. 
Molisch, H. 2002. The influence of one plant on another: allelopathy. L. J. La Fleur and M. A. B. Mallik, translator. Scientific Publishers, Jodhpur, India.

Mylona, P. V., Polidoros, A. N., and Scandalios, J. G. 2007. Antioxidant gene responses to ROS-generating xenobiotics in developing and germinated scutella of maize. J. Exp. Bot. 58:1301-1312.

Romagni, J. G., Allen, S. N., and Dayan, F. E. 2000. Allelopathic effects of volatile cineoles on two weedy plant species. J. Chem. Ecol. 26:303-313.

ROMEO, J. T. 2000. Raising the beam: moving beyond phytotoxicity. J. Chem. Ecol. 26:2011-2014.

Sanchez-Moreiras, A. M., LA Pena, T. C., and Reigosa, M. J. 2008. The natural compound benzoxazolin-2(3H)-one selectively retards cell cycle in lettuce root meristems. Phytochemistry 69:2172-2179.

SINKKONEN, A. 2007. Modelling the effect of autotoxicity on densitydependent phytotoxicity. J. Theor. Biol. 244:218-227.
Song, B. Q., Xiong, J., FAng, C. X., QIU, L., Lin, R. Y., Liang, Y. Y., and LIN, W. X. 2008. Allelopathic enhancement and differential gene expression in rice under low nitrogen treatment. J. Chem. Ecol. 34:688-695.

StebBing, A. R. D. 1982. Hormesis - the stimulation of growth by low-levels of inhibitors. Sci. Total Environ. 22:213-234.

Tomilov, A., Tomilova, N., Shin, D. H., Jamison, D., Torres, M., Reagan, R., McGray, H., Horning, T., Truong, R., NaVA, A., NAVA, A., and Yoder, J. I. 2006. Chemical signalling between plants - mechanistic similarities between phytotoxic allelopathy and host recognition by parasitic plants, pp. 55-69, in M. Dicke, and W. Takken (eds.). Chemical ecology: from gene to ecosystem. Springer, Dordrecht.

WEIDENHAMER, J. 2005. Biomimetic measurement of allelochemical dynamics in the rhizosphere. J. Chem. Ecol. 31:221-236.

ZENG, R. S., and MALLIK, A. U. 2006. Selected ectomycorrhizal fungi of black spruce (Picea mariana) can detoxify phenolic compounds of Kalmia angustifolia. J. Chem. Ecol. 32:1473-1489. 